\title{
9q33.3q34.11 microdeletion: new contiguous gene syndrome encompassing STXBP1, LMX1B and ENG genes assessed using reverse phenotyping
}

\author{
Sophie Nambot ${ }^{1,2}$, Alice Masurel ${ }^{1}$, Salima El Chehadeh ${ }^{1}$, Anne-Laure Mosca-Boidron ${ }^{2}$, \\ Christel Thauvin-Robinet ${ }^{1,3}$, Mathilde Lefebvre ${ }^{1}$, Nathalie Marle ${ }^{2}$, Julien Thevenon ${ }^{1,2}$, Stéphanie Perez-Martin ${ }^{4}$, \\ Véronique Dulieu ${ }^{5}$, Frédéric Huet ${ }^{4}$, Ghislaine Plessis ${ }^{6}$, Joris Andrieux ${ }^{7}$, Pierre-Simon Jouk ${ }^{8,9}$, Gipsy Billy-Lopez ${ }^{8}$, \\ Charles Coutton $^{10}$, Fanny Morice-Picard ${ }^{11}$, Marie-Ange Delrue ${ }^{11}$, Delphine Heron ${ }^{12}$, Caroline Rooryck ${ }^{13}$, \\ Alice Goldenberg ${ }^{14}$, Pascale Saugier-Veber ${ }^{14}$, Géraldine Joly-Hélas ${ }^{15}$, Patricia Calenda ${ }^{16}$, Paul Kuentz ${ }^{3}$, \\ Sylvie Manouvrier-Hanu ${ }^{17,18}$, Sophie Dupuis-Girod ${ }^{19}$, Patrick Callier ${ }^{2,3}$ and Laurence Faivre ${ }^{\star, 1,3}$
}

The increasing use of array-CGH in malformation syndromes with intellectual disability could lead to the description of new contiguous gene syndrome by the analysis of the gene content of the microdeletion and reverse phenotyping. Thanks to a national and international call for collaboration by Achropuce and Decipher, we recruited four patients carrying de novo overlapping deletions of chromosome 9q33.3q34.11, including the STXBP1, the LMX1B and the ENG genes. We restrained the selection to these three genes because the effects of their haploinsufficency are well described in the literature and easily recognizable clinically. All deletions were detected by array-CGH and confirmed by FISH. The patients display common clinical features, including intellectual disability with epilepsy, owing to the presence of STXBP1 within the deletion, nail dysplasia and bone malformations, in particular patellar abnormalities attributed to $L M X 1 B$ deletion, epistaxis and cutaneousmucous telangiectasias explained by ENG haploinsufficiency and common facial dysmorphism. This systematic analysis of the genes comprised in the deletion allowed us to identify genes whose haploinsufficiency is expected to lead to disease manifestations and complications that require personalized follow-up, in particular for renal, eye, ear, vascular and neurological manifestations.

European Journal of Human Genetics (2016) 24, 830-837; doi:10.1038/ejhg.2015.202; published online 23 September 2015

\section{INTRODUCTION}

The majority chromosome 9q33.3q34.11 microdeletions have been reported in a small number of patients diagnosed with Early Infantile Epileptic Encephalopathy type 4 (EIEE4) or Ohtahara syndrome (OS).$^{1-3}$ Indeed, such microdeletions encompassing STXBP1 and leading to the haploinsufficiency of this gene have been defined as one of the main causes of OS. ${ }^{2}$ It is one of the most severe and earliest forms of epilepsy, characterized by various type of seizures in the first days or months of life, a suppression burst pattern on the electroencephalogram (EEG) and severe-to-profound intellectual disability (ID). ${ }^{1}$ Later, nine other patients with a de novo large deletion comprising STXBP1 and the neighboring genes were reported in the literature. ${ }^{4-8}$ One patient included our three genes of interest in her deletion, but clinical description and discussion was only focused on epileptic encephalopathy linked to STXBP1. ${ }^{8}$ Similarly, the clinical description was essentially centered on neurological signs in patients with a microdeletion, including $E N G$, whereas the vascular manifestations of the hereditary hemorrhagic telangiectasia type 1 (HHT1) were not detailed in the majority of cases. ${ }^{1,3,5,7}$ Only Mignot et al. ${ }^{9}$ described a 8-year-old female presenting ID with epilepsy associated with absent thumbnails and hypoplastic nails of the second fingers, respectively attributed to haploinsufficiency of STXBP1 and LMX1B. In this article, we report on the full clinical and molecular characterization of four unreported unrelated individuals with overlapping 9q33.3q34.11 deletions encompassing the STXBP1, LMX1B and ENG

${ }^{1}$ Centre de Génétique et Centre de Référence "Anomalies du Développement et Syndromes Malformatifs", Hôpital d'Enfants, CHU, Dijon, France; ²aboratoire de Cytogénétique, Plateau Technique de Biologie, CHU, Dijon, France; ${ }^{3}$ FHU TRANSLAD, CHU Dijon et Université de Bourgogne-Franche Comté, Dijon, France; ${ }^{4}$ Service de Pédiatrie 1, Hôpital d'Enfants, CHU, Dijon, France; ${ }^{5}$ Service de Soins de Suite et de Réeducation Pédiatrique, Pôle Réeducation Réadaptation, CHU, Dijon, France; ${ }^{6}$ Centre de Compétence des Anomalies du Développement, CHU, Caen, France; ${ }^{7}$ Laboratoire de Génétique Médicale, Hôpital Jeanne de Flandre, CHRU, Lille, France; ${ }^{8}$ Centre de Référence "Anomalies du Développement et Syndromes Malformatifs", Centre Est, CHU, Grenoble, France; ${ }^{~}$ UMR CNRS 5525 TIMC, équipe DYCTIM, CHU, Grenoble, France; ${ }^{10}$ Laboratoire de Génétique Chromosomique, Pôle Couple/Enfants, CHU Grenoble, Université Grenoble Alpes, AGIM CNRS FRE3405 équipe AGC, Grenoble, France; ${ }^{11}$ Centre de Référence des Anomalies du Développement et Syndromes Malformatifs, CHU, Bordeaux, France; ${ }^{12}$ Unité de Génetique Clinique, Hôpital La Pité Salpétrière, Paris, France; ${ }^{13}$ Laboratoire de Génétique Moléculaire, Plateau Technique de Biologie Moléculaire, CHU, Bordeaux, France; ${ }^{14}$ Centre de Compétence des Anomalies du Développement et Syndromes Malformatifs, CHU, Rouen, France; ${ }^{15}$ Laboratoire de Cytologie, Cytogénétique et Biologie de la Reproduction, CHU, Rouen, France; ${ }^{16}$ EEAP Tony Larue, Le Grand Quevilly, France; ${ }^{17}$ Clinique de Génétique Médicale, Hôpital Jeanne de Flandre, CHRU, Lille, France; ${ }^{18}$ Faculté de Médecine, Université Lille 2, Lille, France; ${ }^{19}$ Service de Génétique, Centre de Référence pour la Maladie de Rendu-Osler, Hôpital Femme-Mère-Enfant, Groupe Hospitalier Est, Bron, France

${ }^{*}$ Correspondence: L Faivre, Centre de Génétique, Hôpital d'Enfants, 14 rue Gaffarel, Dijon Cedex 21079, France. Tel: +33 380293 300; Fax: +33 380293266 ; E-mail: laurence. faivre@chu-dijon.fr

Received 24 February 2015; revised 26 July 2015; accepted 30 July 2015; published online 23 September 2015 
genes, gathered from a French national collaboration, allowing to describe a new contiguous gene syndrome.

\section{CLINICAL REPORTS}

All patients were gathered from a collaboration call through AChroPuce and a Decipher search. Consent was obtained from all the patients' families. All clinical features of the patients are summarized in Table 1.

\section{Patient 1}

This 5-year-old girl was the first child of healthy non-consanguineous parents. The pregnancy was complicated by a retroplacental hematoma and severe intrauterine growth retardation. She was born at 27 +5 weeks of gestation (WG) by cesarean section owing to labor failure, with a weight of $950 \mathrm{~g}$ ( $\leq 3 \mathrm{rd}$ centile), length of $34 \mathrm{~cm}(<-4 \mathrm{SD})$ and occipitofrontal circumference (OFC) of $24 \mathrm{~cm}(<-4 \mathrm{SD})$. The Apgar score was 7/10 and she needed intubation during $24 \mathrm{~h}$ and corticotherapy owing to hyaline membrane disease. Equinovarus of both feet, bone demineralization with major skeletal maturation delay and bilateral clinodactyly of the fifth finger were observed. She also suffered from severe chronic constipation. At 2.5 months, her first seizures presented as flexion and clonic spasms of the upper limbs with eye rolling, loss of consciousness and hypotonia in the postcritical phase. EEG showed a disorganized vigil and sleep pattern with suspect bitemporal pattern. Sodium valproate was started, then associated with levetiracetam, given the persistence of the seizures. At the age of 5 months, she was having around one partial seizure a week, sometimes associated with fever. Other types of seizures were also noted, corresponding to bursts of spasms in extension with ocular movements and stertor. A new treatment with vigabatrin and then hydrocortisone $(15 \mathrm{mg} / \mathrm{kg} /$ day $)$ was initiated, but she developed severe status epilepticus with a left temporal focus in a context of bronchitis owing to parainfluenza 3 . The cerebral magnetic resonance imaging (MRI) was normal. She continued to have partial seizures, lasting $5 \mathrm{~min}$, every day, even under treatment. She presented left strabismus and was able to hold her head. At 7 months of age, she underwent surgery for patent ductus arteriosus. At 13 months, the corticotherapy had to be stopped because of the impact on the cardiovascular system even though epilepsy was still not well controlled. At the age of 3 years, weight was $12.8 \mathrm{~kg}$ (25th centile), length was $88 \mathrm{~cm}(-2 \mathrm{SD})$ and OFC was $45 \mathrm{~cm}(-3.5 \mathrm{SD})$. Facial dysmorphism included posterior plagiocephaly, round face, prominent metopic ridge, large and high forehead, highly arched eyebrows, horizontal palpebral fissures, telecanthus, strabismus, bulbous nose, small mouth, thin upper lip, prominent cheeks and square chin (Figure 1a). At the last examination at the age of 5 years, the sitting position was impossible, head tonus was insufficient and she had swallowing disorders for liquids. Severe hypotonia of the trunk and spastic tetraparesis meant she was confined to a wheelchair. She had no language but was described as a very happy and cooperative little girl. Retrospective evaluation revealed bilateral agenesis of the thumbnails, patellar hypoplasia with dislocation of the left patella, abduction of the hips and radio-ulnar synostosis with flexed elbows. Neither telangiectasia nor epistaxis was observed, but she has not yet had investigations for visceral manifestations of the HHT1.

\section{Patient 2}

This 18-year-old girl was born following a dizygotic twin pregnancy at term at 39 WG by cesarean section. Birth weight was $2470 \mathrm{~g}$ (3rd centile) and length was $45 \mathrm{~cm}$ ( $-3 \mathrm{SD}$ ). Clinical dysmorphism included a round face, large and high forehead, highly arched eyebrows, horizontal palpebral fissures, telecanthus, strabismus, dysplastic and low-set ears, bulbous nose, small mouth, thin upper lip, prominent cheeks and a square chin. She was hospitalized 3 times for feeding difficulties. At age 6 months, axial hypotonia with insufficient head control and ataxia were noted. With the help of play therapy, the sitting position was acquired at 17 months, and she began orthoptic re-education. At age 2 years, her weight was at the 3 rd centile, length at $-4 \mathrm{SD}$ and OFC at $-0.5 \mathrm{SD}$. She presented infantile asthma, which evolved favorably without treatment. Skeletal X-rays showed delayed bone age, bilateral bowed radial diaphyses with absent radial cupules and bilateral coxa valga. Walking was acquired at 3.5 years, and static and kinetic cerebellar syndrome was noted, together with hyperlaxity and insufficient coordination. There was no language, and she communicated with her hands or by screaming. Behavioral abnormalities included avoidance of eye contact, vocalizing, stereotypies (hand rubbing and handling objects), voracity and object ingestion. Strabismus was reduced by intensive orthoptic follow-up. Hearing tests were normal. At the age 4 years, she had persistent dysmorphism (Figure 1b) and fingernail dysplasia. The first epileptic seizures appeared at 6 years of age in a context of fever and were characterized by loss of contact, a fixed stare and no reactivity during a few seconds. At the age of 12 years, rare and short tonic-clonic seizures with eye rolling occurred while falling asleep even under treatment (lamotrigine and clonazepam). The EEGs showed anterior slow spikes and waves. Cerebral MRI revealed an atrophic vermis and delayed central myelination. She was treated for thoraco-lumbar scoliosis with double convexity, leg asymmetry, right foot valgus and instability of the patella. Recurrent but sporadic epistaxis was noted without coagulation defects. She had neither telangiectasia, and cerebro-thoracoabdominal scan did not show arterio-veinous malformations. Renal function was normal.

\section{Patient 3}

This 14-year-old girl, the second child of healthy non-consanguineous parents, was born at term and her measurements were $2500 \mathrm{~g}$ for weight (3rd centile), $48 \mathrm{~cm}$ for length $(-2.5 \mathrm{SD})$ and $32 \mathrm{~cm}$ for OFC $(-2 \mathrm{SD})$. She had hypotonia and feeding difficulties, attributed to gastro-esophageal reflux. Facial dysmorphism included brachycephaly, round face, prominent metopic ridge, large and high forehead, highly arched eyebrows, horizontal palpebral fissures, enophtalmia, bulbous nose, small mouth, thin lips, prominent cheeks and square chin. West syndrome was diagnosed at 6 months of age because of infantile spasms and hypsarrhythmia on the EEG, following varicella, treated with vigabatrin, sodium valproate and hydrocortisone. She had infantile asthma that improved at age 3 years. Bone malformations included scoliosis, equinovarus feet, hypoplastic patella and limited elbow extension. At 9.5 years, her weight was $26.4 \mathrm{~kg}$ (25th centile), length was $121 \mathrm{~cm}(-2 \mathrm{SD})$ and $\mathrm{OFC}$ was $48 \mathrm{~cm}(-4 \mathrm{SD})$, and dysmorphism was persistent (Figure 1c). She had severe ID and was in a school for special needs. She could not talk or walk or stand and had severe hypotonia. She was wheelchair-bound. She could only eat blended foods. Behavioral troubles comprised anxiety, manifesting as paroxysms and stereotypy, and abnormal sleep with frequent waking with pain and screams. Outside these periods, she was described as pleasant and happy. Cerebral MRI revealed cortico-subcortical atrophy. Cardiac, abdominal and renal ultrasounds were normal. She had astigmatism and normal hearing tests. At the last examination at age 12 years, frequent epistaxis were observed. She had not displayed seizures since the age of 2 years, when the treatment was stopped. The EEG showed poly spikes and a disorganized pattern. Retrospective 
Table 1 Clinical features of the four index patients

\begin{tabular}{|c|c|c|c|c|}
\hline Patients & Patient 1 & Patient 2 & Patient 3 & Patient 4 \\
\hline Sex & Female & Female & Female & Male \\
\hline Age (years) & 5 & 18 & 14 & 11 \\
\hline Growth delay & + & + & + & + \\
\hline \multicolumn{5}{|l|}{ Facial features } \\
\hline Microcephaly & + & - & + & + \\
\hline Plagiocephaly & + & - & - & + \\
\hline Brachycephaly & - & - & + & - \\
\hline Round face & + & + & + & + \\
\hline Prominent metopic ridge & + & - & + & - \\
\hline Large forehead & + & + & + & + \\
\hline Highly arched eyebrows & + & + & + & - \\
\hline Telecanthus & + & + & - & - \\
\hline Horizontal palpebral fissures & + & + & + & + \\
\hline Strabismus & + & + & - & + \\
\hline Enophtalmia & - & - & + & - \\
\hline Dysplastic ears & - & + & - & Low-set ears \\
\hline Wide saddle nose & - & - & - & + \\
\hline Bulbous nose & + & + & + & + \\
\hline Convex philtrum & - & - & - & + \\
\hline Small mouth & + & + & + & - \\
\hline Thin lips & + & + & + & + \\
\hline Prominent cheeks & + & + & + & + \\
\hline Square chin & + & + & + & + \\
\hline Short and webbed neck & - & - & - & + \\
\hline \multicolumn{5}{|l|}{ Neurological features } \\
\hline Axial hypotonia & + & + & + & + \\
\hline Spastic tetraparesis & + & - & NA & NA \\
\hline Swallowing difficulties & + & + & + & + \\
\hline Cerebellar syndrome & - & + & - & - \\
\hline Walking acquisition & Not acquired & 3.5 years & Not acquired & Not acquired \\
\hline Motor delay & + & + & + & + \\
\hline Speech delay & + & + & + & + \\
\hline Intellectual disability & Severe & Severe & Severe & Severe \\
\hline Behavioral troubles & NA & + & + & NA \\
\hline Epileptic seizures & $\begin{array}{l}\text { Flexion and clonic spasms, } \\
\text { SE }\end{array}$ & Tonic-clonic seizures & West syndrome & Clonic seizures \\
\hline Age at onset of seizures & 2.5 months & 6 years & 6 months & 5 years \\
\hline EEG & $\begin{array}{l}\text { Disorganized vigil and sleep } \\
\text { pattern, left temporal focus }\end{array}$ & $\begin{array}{c}\text { Anterior slow spikes and } \\
\text { waves }\end{array}$ & $\begin{array}{l}\text { Hypsarrhythmia, poly spikes, } \\
\text { disorganized pattern }\end{array}$ & Diffuses spikes waves, slow wakefulness pattern \\
\hline Cerebral MRI & No visible malformation & $\begin{array}{l}\text { Vermis atrophia, central } \\
\text { myelination delay }\end{array}$ & Cortico-cortical atrophy & $\begin{array}{c}\text { Periventricular white matter loss in } \\
\text { semi-oval center regions, } \\
\text { frontal and occipital subcortical areas, T2 hypersignal } \\
\text { lesion of the splenium of the corpus callosum, } \\
\text { myelinization delay of the anterior limbs of the internal } \\
\text { capsules }\end{array}$ \\
\hline \multicolumn{5}{|l|}{ Nail-patella features } \\
\hline Nail dysplasia & + & + & + & + \\
\hline Instability of patellae & + & + & + & + \\
\hline Absent/hypoplastic patellae & Hypoplastic & Hypoplastic & Hypoplastic & Absent \\
\hline Iliac horns & NA & NA & NA & NA \\
\hline Retroversion of neck femoral & - & - & - & - \\
\hline Bilateral coxa valga & - & + & + & - \\
\hline Bowed radial diaphysis & - & + & - & NA \\
\hline Radio-ulnar synostosis & + & - & - & NA \\
\hline Absent radial cupule & - & + & - & - \\
\hline Elbow flexion & + & NA & + & + \\
\hline Equinovarus & + & - & + & + \\
\hline
\end{tabular}


Table 1 (Continued)

\begin{tabular}{|c|c|c|c|c|}
\hline $\begin{array}{l}\text { Bilateral clinodactyly of } \\
\text { finger }\end{array}$ & + & - & - & - \\
\hline Renal disorders & - & - & - & + \\
\hline \multicolumn{5}{|l|}{ HHT1 features } \\
\hline $\begin{array}{l}\text { Visceral vascular } \\
\text { abnormalities }\end{array}$ & NA & - & NS & - \\
\hline \multicolumn{5}{|l|}{ Genital abnormalities } \\
\hline Micropenis & - & - & - & + \\
\hline Hypoplastic scrotum & - & - & - & + \\
\hline Esophagitis & - & - & - & + \\
\hline Infantile asthma & - & + & + & - \\
\hline Patent ductus arteriosus & + & - & - & - \\
\hline $\begin{array}{l}\text { Single transverse palmar } \\
\text { crease }\end{array}$ & - & - & - & + \\
\hline Dorso-lumbar hairy spot & - & - & - & + \\
\hline Constipation & + & - & + & - \\
\hline ID submission LOVD & \#00038515 & \#00038516 & \#00038520 & \#00038521 \\
\hline
\end{tabular}

Abbreviations: +, present; -, absent; NA, not available; NS, not searched; IPP, interphalangeal proximal; SE, status epilepticus.

evaluation revealed hypoplastic nails predominantly affecting the thumbs, but no renal disorder was found.

\section{Patient 4}

This 11-year-old male was the second of two children born to healthy non-consanguineous parents. The family history was unremarkable. The delivery was induced at $41+6$ WG because of abnormal cardiac rhythm and oligamnios, necessitating broncho-aspiration and mask ventilation. The Apgar score was 6/10. Birth weight was $3140 \mathrm{~g}$ (25th centile), length $48 \mathrm{~cm}(-2 \mathrm{SD})$ and $\mathrm{OFC} 33.5 \mathrm{~cm}(-1.5 \mathrm{SD})$. Severe hypotonia was present and severe orthopedic abnormalities were noticed, including flexus adductus thumbs, bent hands with overlapping fingers, limited joint mobility especially at elbows and knees, left equinovarus, talus of the right foot, short and stocky foot and hypoplastic patella. He also had bilateral agenesis of the thumb nails and dysplasia of the other fingernails (Figure 2b). Facial dysmorphism included asymmetric plagiocephaly, round face, high hairline at the temples, horizontal palpebral fissures, strabismus, low-set ears, wide saddle nose, bulbous nose, convex philtrum, thin lips, prominent cheeks, square chin and a short, webbed neck (Figure 1d). A single transverse palmar crease and a $2-\mathrm{cm}$ dorso-lumbar hairy patch were noted. Skeletal X-rays showed limited extension of the elbows and pathological talo-calcaneal divergence. Hypoplastic patella and a mild dilation of the left renal pelvis, which did not require any supervision or treatment, were observed. Clinical and radiological signs allowed to diagnose nail patella syndrome (NPS). At age 1 year, he could roll over but head control was not acquired. The EEG was normal but MRI showed periventricular white matter loss in the semi-oval center regions and in the frontal and occipital subcortical areas. A T2 hypersignal lesion of the splenium of the corpus callosum without white matter defect and a myelinization delay of the anterior limbs of the internal capsules were also observed. Leucodystrophy was evoked but the lesions stability observed on a second MRI 1 year later and metabolic analysis recused this diagnosis. The oto-acoustic emissions were positive and the ophthalmological examination showed alternating convergent strabismus with bilateral astigmatism. The electromyogram and metabolic analysis were normal. At the age of 2.5 years, he could hold his head but there was no sitting position. Language was limited to a few vocalizations and bi-syllables. At the age of 5 years, he presented major thoracic kyphosis with hump of the right hemithorax. $\mathrm{He}$ presented frequent respiratory infections needing respiratory physiotherapy. He had flexed joints and movements of the limbs slowly improved with intention to pick up objects but inability to do so alone. He had some proximal and distal adduction-abduction movements of the arms. He needed a wheelchair with chin and rightsided head support, as well as hand and leg ortheses. He was in a school for severely handicapped children, still eating blended foods and bottle-fed. There was no oral language and communication was mainly visual with mimicking. One episode of seizure was suspected during the night in a context of fever. The EEG worsened and showed permanent and bilateral frontal slow waves associated with spikes exacerbated by light stimulation, without the burst suppression pattern. At the age of 8 years, weight was $13.9 \mathrm{~kg}$ ( $<3 \mathrm{rd}$ centile), length was $100 \mathrm{~cm}(<-4 \mathrm{SD})$ and $\mathrm{OFC}$ was $48.5 \mathrm{~cm}(<-4 \mathrm{SD})$. He developed clonic seizures with abnormal movements of the arms once or twice a week, despite treatment with sodium valproate. An 

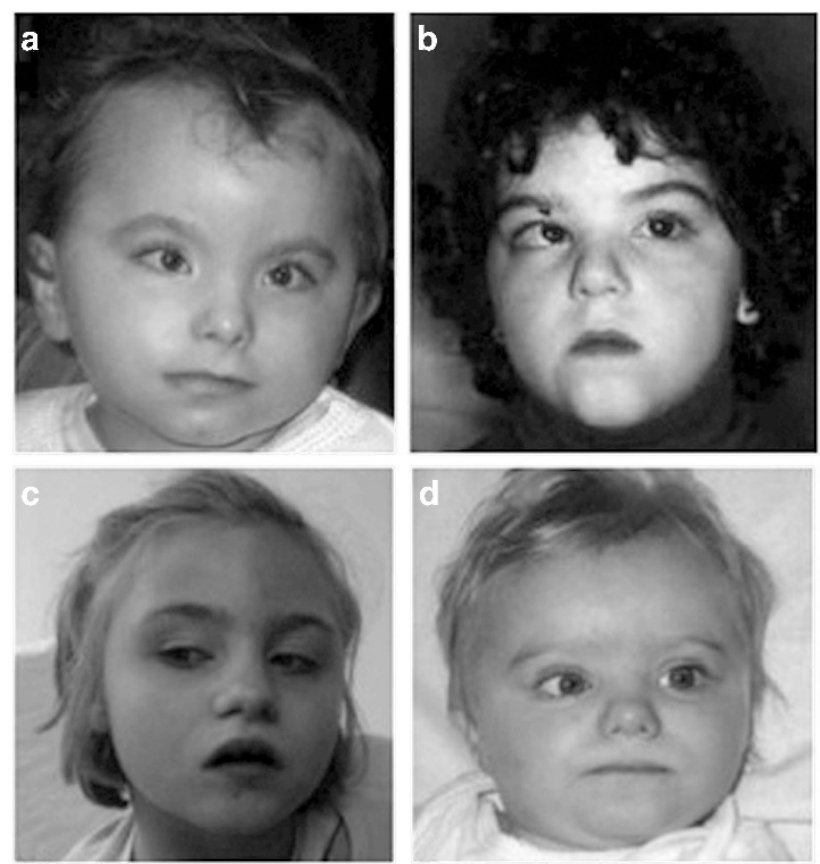

Figure 1 Facial dysmorphism of the four patients. (a) Patient 1 at 3 years and 9 months: Round face, prominent metopic ridge, large and high forehead, highly arched eyebrows, horizontal palpebral fissures, telecanthus, strabismus, bulbous nose, small mouth, thin upper lip, prominent cheeks, and square chin. (b) Patient 2 at 4 years: Round face, large and high forehead, highly arched eyebrows, horizontal palpebral fissures, telecanthus, strabismus, dysplastic and low-set ears, bulbous nose, small mouth, thin upper lip, prominent cheeks, and square chin. (c) Patient 3 at 9.5 years: Brachycephaly, round face, prominent metopic ridge, large and high forehead, highly arched eyebrows, horizontal palpebral fissures, enophtalmia, bulbous nose, small mouth, thin lips, prominent cheeks, and square chin. (d) Patient 4 at 1 year: Asymmetric plagiocephaly, round face, high hairline at the temples, horizontal palpebral fissures, strabismus, low-set ears, wide saddle nose, bulbous nose, convex philtrum, prominent cheeks, thin lips, square chin, and short and webbed neck. A full color version of this figure is available at the European Journal of Human Genetics journal online.

association with lamotrigine permitted a good control of the seizures. Because of the failure to thrive, gastrostomy was necessary associated with an antireflux operation.

At the last examination at age 10 years, he still presented a profound handicap with impossibility to sit or to crawl. Orthopedic signs remained severe with limited mobility (elbows, wrists, hips, knees, ankles). Skeletal X-rays revealed scoliosis, dislocation of the hips, absent patella and bone demineralization (Figure $2 \mathrm{c}$ and d). $\mathrm{He}$ presented abnormal genitalia with hypoplastic scrotum, testicular ectopia and micropenis. Dermatological examinations showed multiple telangiectasias on the cheeks (Figure 2a). He never experienced epistaxis. He presented bronchiectasis of the left lung basis and a rise of the left diaphragmatic cupola that led to desaturation. Computerized tomography scan showed septal hypertrophy and no arteriovenous fistula. Blood pressure, proteinuria and renal function were monitored without anomaly.

\section{MATERIALS AND METHODS}

We searched for patients with a microdeletion that included our three main genes of interest, STXBP1, LMX1B and ENG. We selected these three genes as criteria because the effects of their haploinsufficiency are well demonstrated and the phenotype is characteristic. Array-Comparative Genomic Hybridization Analysis (CGH) was performed using Agilent microarray (Agilent
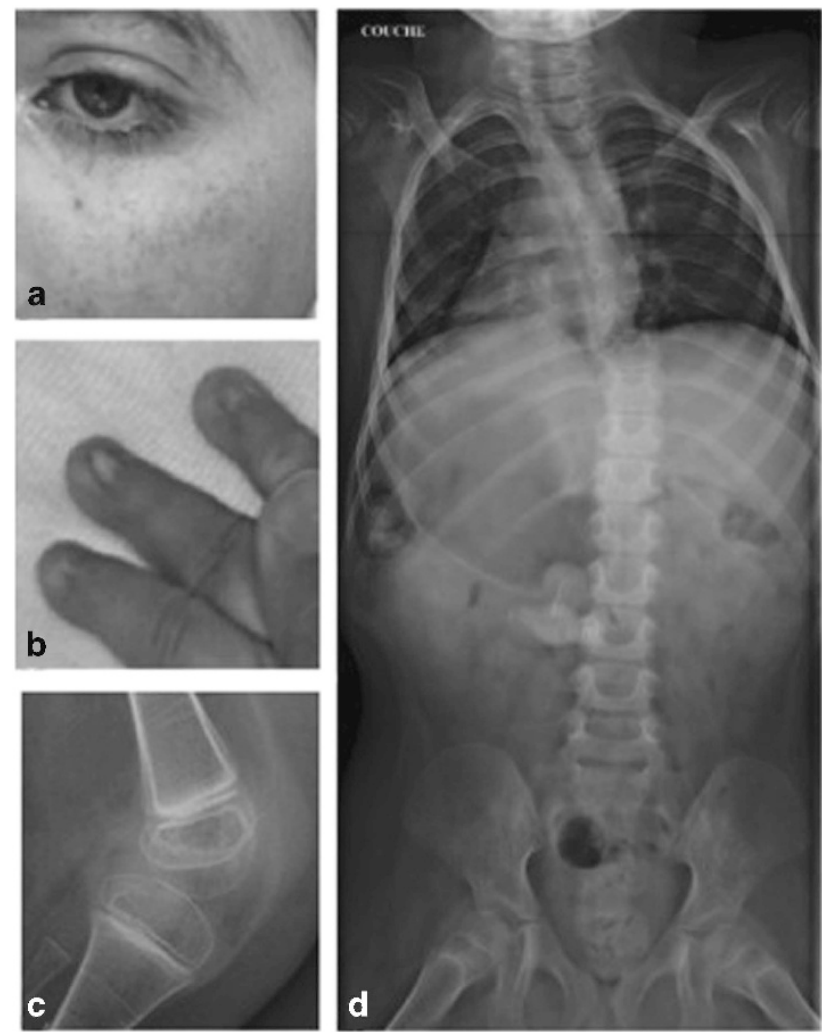

Figure 2 Features of NPS and HHT1 of patient 4. (a) Cutaneous telangiectasias; (b) fingernail dysplasia; (c) absence of patella; (d) scoliosis. A full color version of this figure is available at the European Journal of Human Genetics journal online.

Technologies, Santa Clara, CA, USA), 44K for patients 1 and 3, 180K for patient 2 and $105 \mathrm{~K}$ for patient 4 . Fluorescence in situ hybridization experiments were performed using bacterial artificial chromosome (BAC) clones containing chromosome 9-specific sequences, in accordance with publicly available genome resources (NCBI Map Viewer: http://www.ncbi.nlm.nih.gov; Santa Cruz Human Genome Browser: http://www.genome.ucsc.edu). The BACs were obtained from the RPCI-11 library (BACPAC Resources Center, CHORI, Oakland, CA, USA) and selected according to their positions on chromosome 9. BAC DNAs were labeled by nick translation. The clinical and molecular data of this study have been submitted into the Leiden Open Variation Database (LOVD) (see URLs and Table 1 for the submission ID).

\section{RESULTS}

The molecular and cytogenetic results are presented in Table 2.

\section{DISCUSSION}

We report four patients with a de novo overlapping 9q33.3q34.11 microdeletion. Patients shared a common recognizable phenotype, including facial dysmorphism, epilepsy, ID and features of the NPS and of HHT1. Besides our three genes of interest, this region comprised 12 other genes related to a disease into the Online Mendelian Inheritance in Man database (OMIM), five of which followed an autosomal-dominant inheritance, and one non-OMIM gene potentially involved in the neurological phenotype. The five OMIM genes included LRSAM1, responsible for autosomal-dominant and recessive Charcot-Marie-Tooth (CMT) disease in the minimal critical region of $1.3 \mathrm{Mb}, D N M 1$ recently associated with EIEE31, SPTAN1 responsible for EIEE5 in 3/4 patients, $L R R C 8 A$ responsible for Agammaglobulinemia 5 in 2/4 patients and TOR1A responsible for 
Table 2 Results of array-CGH analysis

\begin{tabular}{|c|c|c|c|c|}
\hline & Patient 1 & Patient 2 & Patient 3 & Patient 4 \\
\hline Size (Mb) & 4.1 & 1.5 & 3.1 & 2.8 \\
\hline Discussed deleted genes & $\begin{array}{l}\text { STXBP1, SPTAN1, LMX1B, ENG, LRSAM1, } \\
\text { TOR1A, LRRC8A, DNM1, SET }\end{array}$ & $\begin{array}{l}\text { STXBP1, LMX1B, ENG, } \\
\text { LRSAM1 }\end{array}$ & $\begin{array}{l}\text { STXBP1, SPTAN1, LMX1B, } \\
\text { ENG, LRSAM1, DNM1 }\end{array}$ & $\begin{array}{l}\text { STXBP1, SPTAN1, LMX1B, ENG, } \\
\text { LRSAM1, LRRC8A, DNM1, SET }\end{array}$ \\
\hline Inheritance & De novo & De novo & De novo & De novo \\
\hline
\end{tabular}

comanases |||||||||C||||||||||||||

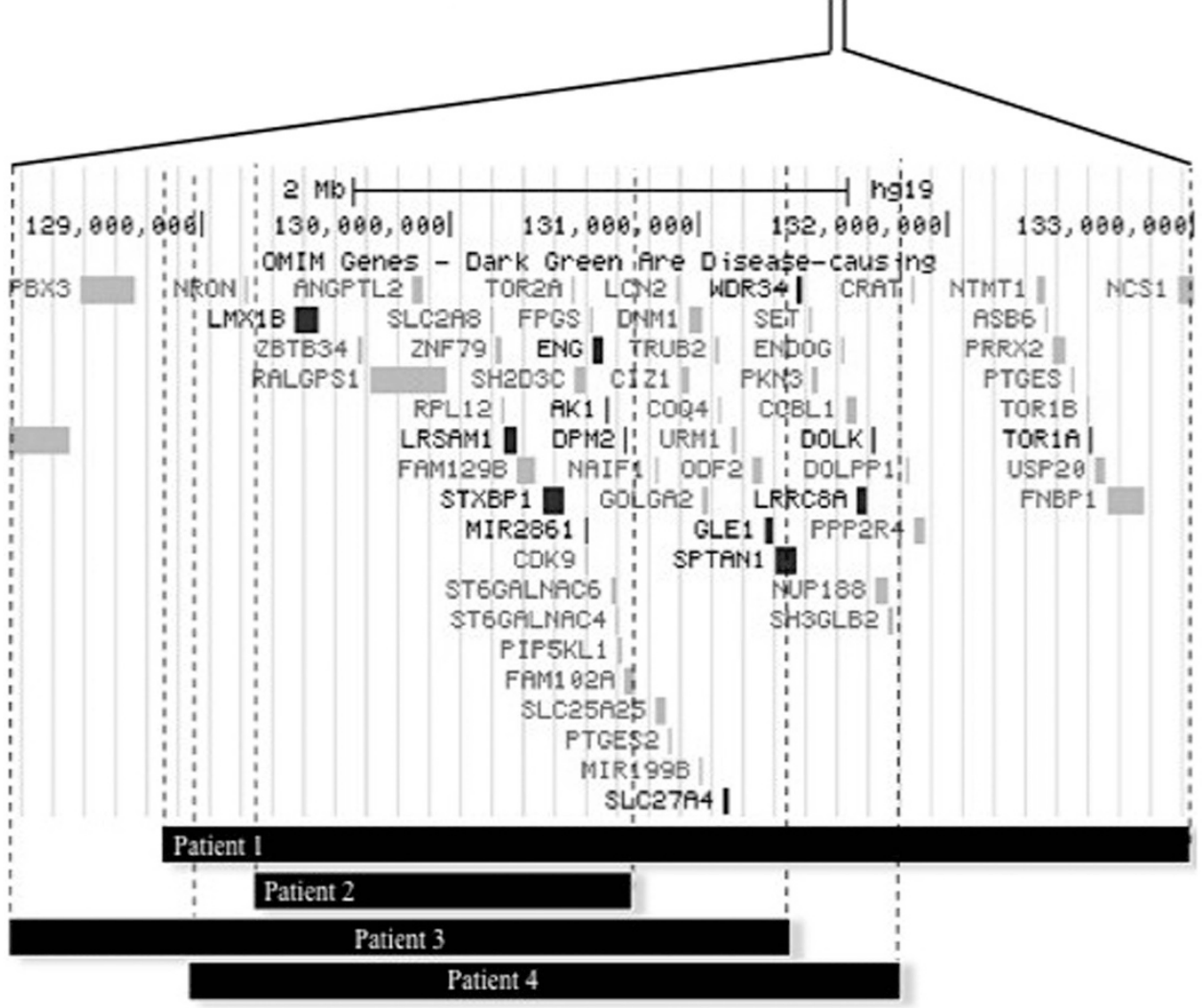

Figure 3 Alignment of the 9q33.3q34.11 deletion of the four index patients.

Torsion Dystonia in patient 2 (Figure 3). The other gene, not yet referred in the OMIM database, is SET, whose de novo truncating variant has been reported in a patient presenting microcephaly and ID.

The epileptic and developmental phenotype is summarized in Table 1. Developmental delay was severe for the four patients including STXBP1 in their deletion. These manifestations could be explained by STXBP1 haploinsufficiency as a large spectrum of epileptic phenotypes with developmental delay has been described from OS to West syndrome, ${ }^{10}$ non-syndromic infantile epileptic encephalopathies and even to one patient with ID but without epilepsy. ${ }^{11}$ STXBP1 encodes syntaxin-binding protein 1 (STXBP1), an evolutionarily conserved neuronal protein that is vital for the process of calcium ion-dependent exocytosis in neurons as well as in neuroendocrine cells. STXBP1, a member of the Sec1/Munc-18 family, binds to syntaxin, thus promoting its stability, and regulates soluble $\mathrm{N}$-ethylmaleimide-sensitive factor attachment protein receptor (SNARE) complex formation with the ensuing priming and fusion of synaptic vesicles. ${ }^{1}$

Interestingly, this chromosomal region also comprises the SPTAN1 gene, which encodes for the Spectrin alpha chain non-erythrocytic 1 protein. Spectrins are a family of filamentous cytoskeletal proteins that function as essential scaffold proteins that stabilize the plasma membrane and organize intracellular organelles. Heterozygous variants in this gene are responsible for EIEE5, characterized by intractable 
tonic seizures, severe-to-profound mental retardation, no speech development and visual attention, hypsarrhythmia, spastic quadriplegia, hypotonia, diffuse hypomyelination, atrophy of the brain, brainstem and cerebellum, thin corpus callosum and progressive microcephaly. ${ }^{12}$ Interestingly, SPTAN1 was not included in the deletion of patient 2 but was deleted in patients 1,3 and 4 . Patient 2 had no microcephaly and could walk, by opposition to the others patients, but she also presented severe ID and MRI anomalies. In the literature, six patients included STXBP1 and SPTAN1 in their deletion and their clinical presentation was EIEE. 1,3,4,7,8 Their EIEE phenotype was likely due to STXBP1 haploinsufficiency, as patients with a deletion involving only SPTAN1 display global development delay and growth delay but did not present epileptic encephalopathy. ${ }^{4,13}$ One recent article argues in favor of a dominant-negative effect in at least a subset of SPTAN1 mutations. ${ }^{14}$

Reverse phenotyping, consisting in refining the clinical phenotype according to genetic data, allowed us to explain the recurrent malformations in our patients. In this series, we highlighted features of NPS and HHT1 disease after analyzing the gene content of the deletions. Indeed, nail dysplasia, scoliosis and absent or hypoplastic patellae was consistent in the four index patients but the diagnosis of NPS had been raised in only one of them before our work. It shows that the diagnosis of a known disease can be difficult in the presence of other confounding features such as ID and marked dysmorphism, and the interest of reverse phenotyping. LMX1B is a member of the LIMhomeodomain family of transcription factors. The protein has two $\mathrm{N}$-terminal LIM domains involving in protein-protein interactions followed by a homeodomain binding to target DNA-binding sites. Disease-causing variants range from various frameshift, nonsense, splice and missense variants to complete gene deletion. The majority of missense variants are found in the homeodomain and the LIM domains. There is great variation in the severity and range of phenotypes both within families that carry the same variant and between families. NPS is an autosomal-dominant human disease characterizing by nail dysplasia, absent or hypoplastic patellae and abnormal elbows along with iliac horns. Nail dysplasia includes longitudinal ridging, abnormally shaped triangular or absent lunulae, slow nail growth, koilonychias and anonychia. Elbow abnormalities may include limited of extension, pronation, and supination, cubitus valgus, and antecubital pterygia. Other bone abnormalities include scoliosis, fifth finger clinodactyly, talipes equinovarus, hypoplasia of first ribs, iliac horns arising from the external iliac fossa and patellar dislocation. ${ }^{15}$ Short stature has been reported in few instances in patients with clinical and radiological diagnosis of NPS. ${ }^{16}$ We therefore cannot conclude if the short stature described in our patients are only explained by the haploinsufficiency of $L M X 1 B$ or also by neighboring genes. In addition, about $30-50 \%$ of patients develop nephropathy, manifesting as proteinuria with or without hematuria, and possibly evolving into nephrotic syndrome and glomerulonephritis. ${ }^{17}$ No renal anomaly, when searched for, was found in this series, but the mean age of the patients was only 12 years. Open angle glaucoma is another feature of the disease and occurs in about $30-40 \%$ of patients. ${ }^{18}$ Sensorineural hearing loss has also been described but was not present in these four patients.

Although most probands were children, 2/4 presented episodes of epistaxis and 1 patient had cutaneous telangiectasias. Genomic deletions involving ENG have been observed in individuals with HHT1, supporting the hypothesis that ENG haploinsufficiency is the molecular pathogenesis of HHT1. Endoglin is a homodimeric membrane glycoprotein primarily associated with human vascular endothelium and a component of the transforming growth factor-beta receptor complex binding (TGFB1). ${ }^{19}$ ENG disruption leads to abnormal vascular development with excessive neovascularization. Clinical features are variable ranging from dilated microvessels to large arterio-venous malformations of skin, mucosa and viscera, with potentially lethal complications. The disorder often presents with early-onset recurrent spontaneous epistaxis, telangiectasias of the skin and mucous membranes occurring in adulthood and increasing with age, pulmonary arterio-venous malformations often revealed by brain abscess or transient ischemic attacks, signs of chronic hypoxia or hemorrhagic rupture. As the clinical phenotype associated with HHT1 tends to develop during childhood and adolescence, it is not surprising that our patients had few or no symptoms. In patients presenting with this $9 \mathrm{q} 33 \mathrm{q} 34$ deletion syndrome, clinical and radiological monitoring is required, as recommended in presymptomatic HHT1 families.

Finally, facial features, which was strikingly similar in all patients, is the only manifestation that cannot be formally explained by one of the known genes in the overlapping segments. Therefore, the implication of a gene that has not been attributed to an OMIM disease is likely and the molecular contribution to facial dysmorphism remains to be determined in this new contiguous gene syndrome.

These observations demonstrate the importance of analyzing the genes comprised in microrearrangements for appropriate monitoring. Indeed, patients will require regular eye, auditory and renal surveillance after the diagnosis of NPS and vascular investigations in the context of haploinsufficiency of the ENG gene, particularly for the pulmonary malformations which can be easily detected by thoracic scan and treated by endovascular treatment, avoiding serious complications. In both diseases, symptoms can be progressive and appear with increasing age.

Of note, the LRSAM1 gene was also deleted in all index patients. Homozygous and heterozygous variants in this gene can cause CMT disease type 2P. Symptoms usually appear in the second or third decade of life on the lower limbs and gradually extend to the upper limbs. We believe that the deletion of LRSAM1 should not lead to features of CMT disease in the future, as patients reported to date either followed autosomal-recessive inheritance in the presence of 2 null alleles or autosomal-dominant inheritance in the presence of heterozygous null variants in the $\mathrm{C}$-terminal domain, thus suggesting a dominant-negative effect. ${ }^{20}$

Likewise, the DNM1 gene, encoding dynamin-1, a GTPase involved in synaptic vesicle endocytosis in the brain during early neuronal development and postnatal synaptic maturation, ${ }^{21}$ is deleted in three out of our four patients. So far, five patients with missense heterozygous de novo variants of DNM1 have been reported. ${ }^{22}$ They all had infantile spasms with onset between 2 and 13 months, and four of which were later diagnosed as Lennox-Gastaut syndrome. They all presented severe-to-profound ID with absence of speech and marked hypotonia. Four of them did not walk and two of them presented generalized cerebral atrophy. Our patient with two copies of DNM1 (patient 2) had a milder neurological phenotype than the other patients.

Concerning TOR1A, we cannot exclude the appearance of signs of Torsion Dystonia in patient 1. Indeed, out of four patients described with complete deletion of this gene in the literature, only one developed clinical signs at the age of 15 years. Incomplete penetrance and age-dependent variable expressivity has been largely demonstrated in this disease. ${ }^{4}$

No agammaglobulinemia was detected in the two patients ( 1 and 4) presenting $L R R C 8 A$ in their deletion.

In fact, the consequence of the deletion of the other dominant OMIM genes remains questionable as the effect of their haploinsufficiency is not known. We tried to analyze whether the data available in the databases could give us pertinent information, including the 
haploinsufficiency score found in Decipher, the presence of null or frameshift alleles present in Exome Variant Server. This was not conclusive for $L M X 1 B$ and $E N G$, although the effect of their haploinsufficiency is well demonstrated. We conclude that the presence in the literature of patients with phenotypic components of the disease and a complete deletion of the gene of interest was the best risk predictor.

Finally, the SET gene, not already reported as an OMIM gene, could be of interest in our patients' phenotype. Indeed, it encodes a multifunctional nuclear protein expressed in various human cell lines and tissues and involved in several pathways. ${ }^{23}$ It interacts with SETBP1, SET-binding protein, whose haploinsufficiency had been reported in association with ID and speech delay. ${ }^{24}$ Recently, a de novo frameshift deletion resulting in a premature stop codon in SET has been identified in a patient with congenital microcephaly, normal brain and moderate ID. ${ }^{25}$ SET is deleted in two of our four patients, but it is difficult to determine the weight of SET deletion in the phenotype of our patients, relative to the loss-of-function of other STXBP1, SPTAN1 and DNM1.

In conclusion, we report a new $9 \mathrm{q} 33.3 \mathrm{q} 34.11$ contiguous gene syndrome based on the description of four new patients. With the development of new technologies, such as next-generation sequencing, a new approach of genetic diseases had developed, called reverse phenotyping. This consists of the refinement of clinical phenotype based on the genetic data to unravel the genetic cause of a disease. This approach should be more largely developed for the description of new microdeletionnal syndromes as well as for accurate follow-up.

\section{CONFLICT OF INTEREST}

The authors declare no conflict of interest.

\section{ACKNOWLEDGEMENTS}

We thank the regional council of Burgundy for financial support, as well as the patients and families for their contribution.

1 Saitsu H, Kato M, Mizuguchi T et al: De novo mutations in the gene encoding STXBP1 (MUNC18-1) cause early infantile epileptic encephalopathy. Nat Genet 2008; 40: 782-788.

2 Tohyama J, Akasaka N, Osaka $\mathrm{H}$ et al: Early onset West syndrome with cerebral hypomyelination and reduced cerebral white matter. Brain Dev 2008; 30: 349-355.

3 Saitsu H, Kato M, Shimono M et al: Association of genomic deletions in the STXBP1 gene with Ohtahara syndrome. Clin Genet 2012; 81: 399-402.
4 Campbell IM, Yatsenko SA, Hixson P et al: Novel 9q34.11 gene deletions encompassing combinations of four Mendelian disease genes: STXBP1, SPTAN1, ENG, and TOR1A. Genet Med 2012; 14: 868-876.

5 Matsumoto H, Zaha K, Nakamura Y, Hayashi S, Inazawa J, Nonoyama S: Chromosome 9q33q34 microdeletion with early infantile epileptic encephalopathy, severe dystonia, abnormal eye movements, and nephroureteral malformations. Pediatr Neurol 2014; 51 . $170-175$.

6 Nicita F, Ulgiati F, Bernardini L et al: Early myoclonic encephalopathy in 9q33-q34 deletion encompassing STXBP1 and SPTAN1. Ann Hum Genet 2015; 79: 209-217.

7 Mastrangelo M, Peron A, Spaccini L et al: Neonatal suppression-burst without epileptic seizures: expanding the electroclinical phenotype of STXBP1-related, early-onset encephalopathy. Epileptic Disord 2013; 15: 55-61.

8 Barcia G, Chemaly N, Gobin S et al: Early epileptic encephalopathies associated with STXBP1 mutations: could we better delineate the phenotype? Eur J Med Genet 2014; 57: 15-20.

9 Mignot C, Moutard ML, Trouillard 0 et al: STXBP1-related encephalopathy presenting as infantile spasms and generalized tremor in three patients. Epilepsia 2011; 52: 1820-1827.

10 Deprez L, Weckhuysen S, Holmgren P et al: Clinical spectrum of early-onset epileptic encephalopathies associated with STXBP1 mutations. Neurology 2010; 75: 1159-1165.

11 Hamdan FF, Gauthier J, Dobrzeniecka S et al: Intellectual disability without epilepsy associated with STXBP1 disruption. Eur J Hum Genet 2011; 19: 607-609.

12 Saitsu H, Tohyama J, Kumada T et al: Dominant-negative mutations in alpha-II spectrin cause West syndrome with severe cerebral hypomyelination, spastic quadriplegia, and developmental delay. Am J Hum Genet 2010; 86: 881-891.

13 Tzschach A, Grasshoff U, Schäferhoff K et al: Interstitial 9q34.11-q34.13 deletion in a patient with severe intellectual disability, hydrocephalus, and cleft lip/palate. Am J Med Genet A 2012; 158A: 1709-1712.

14 Tohyama J, Nakashima M, Nabatame S et al: SPTAN1 encephalopathy: distinct phenotypes and genotypes. J Hum Genet 2015; 60: 167-173.

15 Sweeney E, Hoover-Fong JE, McIntosh I: Nail-Patella Syndrome. GeneReviews 19932015, 31 May 2003 (updated 13 November 2014).

16 Haddad S, Ghedira-Besbes L, Bouafsoun C et al: Nail-patella syndrome associated with short stature: a case series. Case Rep Med 2010; 2010: pii: 869470.

17 Sweeney E, Fryer A, Mountford R, Green A, McIntosh I: Nail-Patella Syndrome: a review of the phenotype aided by developmental biology. J Med Genet 2003; 40: 153-162.

18 Mimiwati Z, Mackey DA, Craig JE et al: Nail-patella syndrome and its association with glaucoma: a review of eight families. Br J Ophthalmol 2006; 90: 1505-1509.

19 Rius C, Smith JD, Almendro N et al: Cloning of the promoter region of human endoglin, the target gene for hereditary hemorrhagic telangiectasia type 1. Blood 1998; 92: 4677-4690.

20 Engeholm M, Sekler J, Schöndorf DC et al: A novel mutation in LRSAM1 causes axonal Charcot-Marie-Tooth disease with dominant inheritance. BMC Neurol 2014; 14: 118

21 Boumil RM, Letts VA, Roberts MC et al: A missense mutation in a highly conserved alternate exon of dynamin-1 causes epilepsy in fitful mice. PLoS Genet 2010; 6: pii: e1001046.

22 EuroEPINOMICS-RES Consortium; Epilepsy Phenome/Genome Project; Epi4K Consortium: De novo mutations in synaptic transmission genes including DNM1 cause epileptic encephalopathies. Am J Hum Genet 2014; 95: 360-370.

23 Muto S, Senda M, Akai Y et al: Relationship between the structure of SET/TAF-lbeta/ INHAT and its histone chaperone activity. Proc Natl Acad Sci USA 2007; 104: 4285-4290.

24 Coe BP, Witherspoon K, Rosenfeld JA et al: Refining analyses of copy number variation identifies specific genes associated with developmental delay. Nat Genet 2014; 46: 1063-1071.

25 Hamdan FF, Srour M, Capo-Chichi JM et al: De novo mutations in moderate or severe intellectual disability. PLoS Genet 2014; 10: e1004772.

Supplementary Information accompanies this paper on European Journal of Human Genetics website (http://www.nature.com/ejhg) 